\title{
Toward effective government communication strategies in the era of COVID-19
}

\author{
Bernadette Hyland-Wood (iD ${ }^{1 凶}$, John Gardner ${ }^{2}$, Julie Leask $\mathbb{D}^{3}$ \& Ullrich K. H. Ecker (i) ${ }^{4}$
}

Several countries have successfully reduced their COVID-19 infection rate early, while others have been overwhelmed. The reasons for the differences are complex, but response efficacy has in part depended on the speed and scale of governmental intervention and how communities have received, perceived, and acted on the information provided by governments and other agencies. While there is no 'one size fits all' communications strategy to deliver information during a prolonged crisis, in this article, we draw on key findings from scholarship in multiple social science disciplines to highlight some fundamental characteristics of effective governmental crisis communication. We then present ten recommendations for effective communication strategies to engender maximum support and participation. We argue that an effective communication strategy is a two-way process that involves clear messages, delivered via appropriate platforms, tailored for diverse audiences, and shared by trusted people. Ultimately, the long-term success depends on developing and maintaining public trust. We outline how government policymakers can engender widespread public support and participation through increased and ongoing community engagement. We argue that a diversity of community groups must be included in engagement activities. We also highlight the implications of emerging digital technologies in communication and engagement activities.

\footnotetext{
${ }^{1}$ School of Political Science and International Studies, The University of Queensland, Brisbane, QLD 4072, Australia. ${ }^{2}$ School of Social Sciences, Monash University, Melbourne, VIC 3800, Australia. ${ }^{3}$ Susan Wakil School of Nursing and Midwifery, University of Sydney, Camperdown, NSW 2006, Australia.

${ }^{4}$ School of Psychological Science, University of Western Australia, Crawley, WA 6009, Australia. ${ }^{凶}$ email: b.hylandwood@uqconnect.edu.au
} 


\section{Introduction}

- he COVID-19 pandemic has caused hundreds of thousands of deaths and has been responsible for a global economic downturn. Not all countries, however, have been affected equally, with the initial response in some countries relatively successful in suppressing transmission of the SARSCoV-2 virus. For example, by the second week of December 2020, Australia had reported a rate of 1094 cases and 35 deaths per million population. While numbers were even lower in New Zealand-420 cases and five deaths per million-Australia's rate stands in contrast with, for example, the United States, with rates of 51,655 cases and 937 deaths per million and the United Kingdom with 27,746 cases and 954 deaths per million. ${ }^{1}$

Naturally, many factors contributed to Australia's relative success, including its geographic isolation and wealth. However, all government levels (Federal, States and Territories, and local councils) responded quickly and decisively (Swerrisen, 2020). In the crucial early phase, there was strong concordance between public health advice and action by leaders. The public response included the rapid and reasonably widespread uptake of a range of preventative behaviours, including physical distancing (also referred to as social distancing) with a general focus on 'flattening the curve.' In early April 2020, the Australian Government Department of Health sought advice from a rapidly-formed multidisciplinary task force comprising experts from the country's eight leading universities (known as the Group of Eight, or Go8). This taskforce prepared an independent report titled COVID-19 Roadmap to Recovery: A Report for the Nation (Group of Eight Universities, 2020) presented to the National Cabinet and Australian Government in May 2020. The report contained evidence-informed recommendations from a range of researchers and practitioners in epidemiology, infectious disease management, First Nations scholars, and social scientists. In this report, public health communication was considered central to addressing the pandemic, and it was defined as a two-way process engaging policymakers and communities. The paper presented here expands on the same authors' communications guidance for the task force report. ${ }^{2}$

This paper aims, informed by the literature from the fields of applied risk communication, cognitive and social psychology, sociology, and public policy, to guide pandemic communications strategies. The combination of insights spanning multiple disciplines has been neglected in the risk and crisis communications literature, and it is the purpose of this paper to combine these complementary fields. The derivation of the foundations and recommendations presented here resulted from collaborative discussions and critical analysis, based on the authors' disciplinary expertise ${ }^{3}$ and synthesis of the relevant literatures. The analysis scope was public health crisis communications advice, as provided in the COVID-19 Roadmap to Recovery report (Group of Eight Universities, 2020).

This paper argues that effective communication during a public health crisis is not merely about messaging. Instead, it is"an interactive process of exchange of information and opinion among individuals, groups, and institutions. It involves multiple messages about the nature of risk and other messages, not strictly about risk, that express concerns, opinions or reactions to risk messages or legal and institutional arrangements for risk management" (National Research Council, 1989, p. 21). Accordingly, pandemic risk communication requires ongoing engagement with communities. It must consider an evolving technical knowledge of the pathogen and its epidemiology and relevant social dynamics, socio-cultural diversity, and a rapidly-changing media landscape.

In this complex space, contested knowledge, values, and perspectives produce tensions in policymaking and, thus, communication (Cairney, 2015; Cash et al., 2003; Head, 2016). Evidence can be patchy, especially during rapidly changing situations such as a pandemic, and ideological factors may impact its evaluation (Head, 2010a, 2010b; Parkhurst, 2017a, 2017b; Sanderson, 2009). Also, empirical evidence is just one of the many factors driving policymaking (Alford and Head, 2017; Parkhurst and Abeysinghe, 2016). Even sound decisions are likely to be challenged when addressing complex crises due to underlying value differences (Head, 2010a, 2010b; Mols et al., 2020; Parkhurst, 2017a, 2017b; Parkhurst and Abeysinghe, 2016). Communicators, therefore, should anticipate disagreement due to the contestation of the legitimacy of expertise, especially in areas that cut across a range of policy areas and disciplinary boundaries and draw on sometimes competing values (Cairney, 2016; Head, 2007). Policy studies encourage us to move beyond a naïve perspective that there is a direct connection between an evidence base and an optimal public health communication strategy.

We also note at the outset that message conveyance and message development are not independent. Successful delivery and impact of a message will in part depend on the process by which the conveyed content (e.g., a pandemic response strategy) is created. Vice versa, broad support for a particular message, action plan, or strategy will depend on how its development process is communicated. Moreover, the specifics of the chosen strategy will, to some degree, determine the communication approach (e.g., core target audiences).

We argue that effective communications and leadership are central to the management of pandemics and the rapidly changing societal and economic landscape. The empirical evidence from Australia's initial response in early 2020 is supported by scholarly research: Communications strategies, when done well by agencies, can facilitate public trust, confidence, and, importantly, compliance with the behaviours needed from individuals, communities, organisations, and nations (Carter et al., 2011; Siegrist and Zingg, 2014). During a public health crisis, the governments' role includes enlisting public trust and cooperation to be part of the solution (Jetten et al., 2020; Levy, 2020; Siegrist and Zingg, 2014). Ideally, message development should be evidence-informed and transparent and based on engagement with relevant stakeholders, and communication should be considered an integral aspect of content development (Covello, 2003; Everett et al., 2020; National COVID-19 Health and Research Advisory Committee, 2020). We will touch on these interdependencies as they become relevant in the following sections.

People's engagement with and response to public health information and messaging is heavily influenced by their cultural and social identity, age, gender, and access to resources. These factors influence people's preferred modes of communication, who and what they perceive as a 'trustworthy authority,' and, importantly, their capacity to act and respond to information. The evidence-based policy literature details issues related to different forms of knowledge regarding salience, credibility, and legitimacy across geographies and jurisdictions (Cash et al., 2003; Tangney, 2017). It cannot be ignored that in the 'post-truth era,' government communications is seen by some to be inherently political and value-laden (Cairney, 2016; Lewandowsky et al., 2017; Mulgan, 2005).

Drawing on social-psychological research, identity leadership advances the notion of fostering a shared sense of belonging and purpose about a mission (Haslam et al., 2011), with effective identity leadership seeking to incorporate core values and shared goals (Mols et al., 2020; Steffens et al., 2014). Avoiding exposure to a highly transmissible disease or taking care of family, neighbours, and staff may be shared goals; however, the mode of delivery and the framing of vital public health information needs 
to be sensitive to and tailored towards specific social groups and communities (Kreuter et al., 1999; Moser, 2010). For example, research with First Nations communities in eastern Australia after the 2009 H1N109 influenza pandemic showed it was necessary to understand community perspectives and needs first; to work with local influencers-'go-to people'-and include culturally-relevant advice around managing risk in households and at funerals (Massey et al., 2009). While increased interaction and shared identity will not ensure high-levels of trust and mutual understanding, they are indispensable tools for communicators.

Moreover, societal factors must be taken into account when developing a public health communication strategy, which, to be genuinely effective in engaging maximum public support and participation, needs to be sensitive to the concerns and values of diverse publics, and work with different modes of information sharing. The recent proliferation of information available via online media provides an additional layer of complexity. Television and printed news media, which in the past have been an essential conduit for circulating public health information, must now compete with a vast array of easily accessible social media and online news and opinion sources. In particular, social media is highly engaging and encourages users to share stories, images, and opinions (Dobson et al., 2018). The uptake of social media signifies an era in which the public actively participates in creating and circulating influential messaging (Burgess and Green, 2018). One consequence of this is the proliferation of misinformation that can intensify anxiety and exacerbate social tensions and discriminatory behaviours (Lewandowsky et al., 2017; Waszak et al., 2018). Social media, however, also provides opportunities for effective communication. It enables vital messages to be disseminated quickly and efficiently and to be appropriately tailored to different audiences. It also allows communities to themselves to become actively involved in sharing and honing relevant messages.

As stated above, trust is widely recognised as being a central pillar of effective public health crisis management. Below, we argue that the establishment of trust requires transparency and civic engagement. We then identify a set of ten recommendations for effective pandemic communication, drawing primarily on scholarship from the disciplines of risk communication, social and cognitive psychology, and policy studies. These recommendations are designed to form building blocks of an overarching communications strategy that respects the diversity of communities that constitute contemporary societies (Moser, 2010) and reflects a commitment to community participation. We do not envisage these recommendations as an ordered hierarchy. Some recommendations overlap, and there are synergistic relations, and in some cases, tensions between them. While we relate some of the recommendations to the COVID-19 pandemic and illustrate how Australian authorities successfully implemented elements during the initial outbreak of COVID-19, we argue that the recommendations can be applied to other public health and national challenges that traverse the domains of social life, economy, and health. In the final section, we consider on the role of digital technologies sometime used to support contract tracing and public health responses.

\section{Pandemic communications: foundations and recommendations}

Foundations. Public trust is a critical resource in harnessing public cooperation and sustaining the behaviours needed for pandemic management (Agley, 2020; Devine et al., 2020). Siegrist and Zinng (2014) argue that successful crisis communication in a pandemic depends on high levels of trust contingent on shared values between actors and includes confidence that future developments will occur as expected. Siegrist and Zinng also stress that a transparent information strategy is necessary to enable people to act and assert that transparency failures can undermine trust in institutions. Indeed, public trust can rapidly erode and remain low when government leaders appear unwilling to follow the rules and guidelines expected of the general public (Fancourt et al., 2020). ${ }^{4}$

Indeed, governments should prioritise transparency, especially in situations where they need to act rapidly and with limited consultation for the greater good, as is often the case in health emergencies. Trust in government and organisations is enhanced when there is transparency in the information presented and the decision-making process. Transparent communication in a public health crisis includes disclosing what evidence was used to inform public-health recommendations, who was consulted, and what scenarios and trade-offs were considered.

Since a coherence of values is conducive to trust, civic engagement (or community engagement) is necessary to identify shared values and enable communities and social networks to be involved in the decisions that will affect them (Adler and Goggin, 2005; Miranti and Evans, 2019). Meaningful stakeholder engagement can improve containment measures' effectiveness (Renn, 2008; Renn and Walker, 2008) and encourage greater ownership of decisions and more chance of public cooperation (Head, 2007, 2011). Stakeholder engagement stands in contrast to the now much-derided (but still operational) 'deficit model' in communications research, in which communication is envisaged as a one-way mechanism of 'educating an ignorant public' (Meyer, 2016). The deficit model homogenizes 'the public,' and ignores the critical role that people's local expertise, values, and experience can play in shaping and facilitating implementable policy interventions (Wynne, 2006).

Civic engagement can, of course, be challenging in times of crisis when governments must make rapid, life-saving decisions that may require imposing strict measures with little or no time for community involvement. These measures themselves can also be life-changing. The economic and societal costs associated with the response to the COVID-19 pandemic will continue to be felt long after restrictions are eased (Allen et al., 2020). However, recovery will be fostered by active and ongoing public participation and engagement with communities, industries, organisations, and other stakeholders to ensure that concerns and aspirations are understood and considered (Covello, 2003; Head, 2007, 2011). In Australia, the initial success in reducing the rate of transmission, combined with a sense of social solidarity through messaging (also see New Zealand's 'team of five million'), has provided a valuable window of opportunity to establish deliberative processes. Social groups, businesses, and organisations can influence the containment measures that are likely to affect them and the pathway to recovery (Allen et al., 2020; Cammett and Lieberman, 2020). Such a consultative approach is by no means radical. Civic engagement, including community and industry consultation, has been a purposeful policymaking component in many OECD countries such as Australia for several decades (Head, 2011). There already exists a wealth of expertise and experience among governments, communities, industry, and academia. In times of crisis, these resources must be mobilised.

Recommendations for communication. We now detail ten recommendations for the development and delivery of public health crisis communications. All ten recommendations reflect the importance of transparency and civic engagement in establishing trust, which is critical to effective communication.

Recommendation 1-Engage in clear communication. Especially during times of crisis, it is essential to provide specific information on what to do and what to avoid, which can reduce anxiety 
and maintain order. For example, messaging might focus on concrete actions (e.g., 'keep $1.5 \mathrm{~m}$ apart at all times'; 'ban all gatherings of more than five people') and specific periods (e.g., 'from Sunday, gatherings of ten people will be allowed'). People consider messages relevant when they both affect their lives and require relatively little processing effort (Wilson and Sperber, 2002). Cognitive processing effort can be minimised by using grammatical forms that match the message, namely declarative statements for information and imperative statements for directives (Thompson, 2013). Clear instructions are especially important when some restrictions are eased but not others. For example, when schools reopen after a period of closure, parents may reasonably assume that parent school-gate gatherings are also acceptable.

Some inconsistent messaging will be unavoidable due to the rapidly changing nature of a pandemic, especially when jurisdictions vary in their responses (e.g., different regions might choose different strategies, or localised outbreaks might lead to localised restrictions). However, at any one point in time, communicators should aim for consistent messages and terminology. Communications across various channels (e.g., across national and local/ subnational governments, across communication channels, and especially within a government) need to be coordinated to achieve maximum consistency. For example, if all relevant authorities consistently state that 'all people must wear a fitted face-mask when leaving their home,' the message will be more effective. Recognise that coordination will be challenging in polarised environments or when fundamental disagreements exist between national and subnational approaches; however, communication benefits from cooperation and consensus position, where possible (e.g., committing to a transparent communications approach, using shared terminology). Building trust can be enhanced by communicating regularly (e.g., at fixed times) across many channels. In general, communications should be tested for clarity and effectiveness a priori where possible. Furthermore, policymakers and communications personnel are encouraged to work in consultation with subject matter experts across different jurisdictions to adopt a uniform public-health alert system. For example, communicating with a uniform colour-coded warning system or a numeric system for restriction stages allows people to see and plan; advice can also be geo-targeted according to risk level.

Recommendation 2-Strive for maximum credibility. Credibility is essential to effective, persuasive communication (Briñol and Petty, 2009). Strategies for achieving maximum credibility during a pandemic response include leveraging trusted, authoritative intermediaries such as medical and public-health experts to communicate key messages. To an extent, such roles are hardwired into the public-health governance of many countries (e.g., Chief Medical Officers in some Commonwealth countries), although this does not guarantee that governments will listen to the expert's advice and support them in their role. Trust in healthcare professionals, scientists, and expert medical organisations has generally remained high despite the public's confidence in governments being low (Funk and Kennedy, 2019). In some cases, the public is more likely to support policy advanced by technical or health policy experts legitimised through institutions and embedded in policy networks (Lewis, 2006; Martin et al., 2019). While political leaders typically announce crucial policy decisions, citizens have responded more favourably to policy proposals advanced by trusted public health officials (Martin et al., 2019). Such an approach will help communicate that policies and directions are underpinned by appropriate evidence and apolitical guidance, especially when trust in government is low or challenged by popular opinion (Funk and Kennedy, 2019).
Given that trust arises from perceived expertise, honesty, and care (Peters et al., 1997), policymakers and communicators must be seen to be referring to the best available knowledge and evidence, and where possible, expert consensus (Lewandowsky et al., 2013). Engagement is optimal when using those who have relevant training, expertise, and trust within their networks. This again implies that different audiences will, to some extent, benefit from various messengers (Kreuter et al., 1999; Moser, 2010). Beyond the immediate efficacy of messaging, greater credibility can also encourage people to consult authoritative sources, including government health websites, for information and guidance.

Public trust in experts is not automatic and cannot be taken for granted (Whyte and Crease, 2010). In a rapidly shifting landscape characterised by a pluralisation of expertise and reduced personalisation, health organisations and professionals need to find new ways to build and maintain trust (Kuhlmann, 2006). Approaches might include fostering trust in science, identifying ways for citizens to participate in research, and improving science communication (Boele-Woelki et al., 2018), community engagement (Pham, 2016; also see Wynne, 2006, for critical analysis), and the adoption of open-science practices (Funk and Kennedy, 2019; Grand et al., 2012). This will be particularly important in situations where attacks on scientific expertise by segments of the media and political actors are commonplace and contribute to science denial and opposition to evidence-based policy (Bursztyn et al., 2020; Gauchat, 2012; Leiserowitz et al., 2013; Lewandowsky et al., 2016; Lewandowsky and Cook, 2020; Simonov et al., 2020). While a crisis presents an opportunity to build public trust by engaging in honest and transparent communication, as detailed in this paper, trust can also be rapidly lost if the expert is perceived as a political pawn or their credibility is attacked. Moreover, in a prolonged crisis, public trust can be compromised by a senior public-health expert's dual roles-providing evidenceguided advice to the government and the public and acting as a spokesperson for government-if there is tension between those roles.

Recommendation 3-Communicate with empathy. When communicating, leaders should listen to the community's needs and concerns and express genuine empathy and concern. They should not fear expressing empathy or showing emotion (Seeger, 2006). Expression of compassion enhances credibility and leads to more effective communication (Reynolds and Quinn, 2008). The more citizens sense that politicians empathize with them and are concerned for their wellbeing, the more likely will they respond favourably to the advice given (Pfattheicher et al., 2020).

Leaders can empathise by explicitly recognising and seeking ways to alleviate the hardships people may experience. This could be done via short narratives, such as talking about the struggle of a specific person affected by the virus or a person who lost their job and must support their family-although we hasten to add that such anecdotes cannot and should not be engaged in place of proper policy action. Leaders should also communicate respect and a belief that they trust the public, as this is more likely to elicit cooperation (van Bavel et al., 2020; Leask and Hooker, 2020). Finally, leaders should praise groups or sectors of people on the front line and follow the provided guidance. This feedback is both a form of constructive engagement with citizens and can encourage ongoing maintenance of positive behaviours (Chudleigh et al., 2004).

Recommendation 4-Communicate with openness, frankness, and honesty. People are more likely to follow advice if they understand the rationale behind it. Therefore, it is vital to explain 
why particular actions are essential, helpful, or problematic (e.g., 'we must observe physical distancing to protect vulnerable populations from exposure') and the basis on which decisions are being made. 'Sugar-coating' should be avoided: Access to accurate information, both positive and negative, helps people build proper expectations. The aim should not be to scare people but to provide sufficient information to be appropriately worried (Petersen, 2020; Sandman and Lanard, 2020). Risk perception can be a predictor of protective behaviours (Wise et al., 2020), and thus risks should neither be exaggerated nor trivialized. When change is at hand, leaders should communicate early, even with incomplete information. While people dislike uncertainty, a perception of obfuscation is worse because it diminishes trust. Acknowledging uncertainty does not undermine confidence in the information or its source (van der Bles et al., 2020). Moreover, withholding information can motivate people to look for information elsewhere, fostering a belief in rumours, misinformation, and conspiracy theories (Kovic and Füchslin, 2018).

Recommendation 5-Recognise that uncertainty is inevitable. Since people generally dislike ambiguity (Han et al., 2018), it is essential to provide certainty where possible, help people prepare for the immediate and longer-term future both pragmatically and mentally, and reduce the anxiety resulting from uncertainty. However, by their very nature, health emergencies contain uncertainty. Therefore, it is equally important not to foster illusions of certainty, which could lead to the erosion of trust-an essential resource. Communicators may be tempted to overreassure as a way to reduce public fear and manage their concerns (Sandman and Lanard, 2020). However, intense risk negations (e.g., 'it is perfectly safe') may backfire and cause people to become more risk-averse (Betsch and Sachse, 2013). Instead, recognise that risks exist and that uncertainty and ambiguity are inevitable and proceed from that common ground. This is supported by a recent review that concluded that forms of technical uncertainty (quantified error ranges and probabilities) had nil or positive effects on beliefs or intentions. In contrast, consensus uncertainty had negative effects (Gustafson and Rice, 2020).

As new findings and evidence emerge, particular care should be taken to communicate shifts in approach, as this can easily lead to the perception of inconsistency. A change in direction should not be glossed over. On the contrary, as new evidence emerges, acknowledging the uncertainties and emphasizing the conflict between the old and new information can facilitate knowledge revision (Ecker et al., 2017; Kendeou et al., 2014). When dealing with optimistic recipients, it may be necessary to point out that uncertainty means that outcomes can be worse than expected, meaning uncertainty is all the more reason to act to avoid negative consequences rather than being complacent and hoping for the best (Lewandowsky et al., 2014).

Recommendation 6-Account for levels of health literacy and numeracy. An essential task during a pandemic is to communicate in a manner that considers variations in health literacy and numeracy across audiences. Health literacy refers to how people understand health and health care and how they can apply that information within their daily lives to make more informed decisions (Australian Commission on Safety and Quality in Health Care and Australian Institute of Health and Welfare). On a basic level, people's capacity to perform behaviours to minimize infection risk effectively rests on a basic understanding of microorganisms and their transmission. Some people may not possess this knowledge and need to learn how to protect themselves and those around them (furthermore, in the specific case of COVID-19, information about the virus's characteristics, for example, regarding its transmission by air, is rapidly evolving). Similarly, the capacity to understand probabilities and risks rests on how people process quantitative information. Studies have shown that probabilities and percentages are often misunderstood (Gigerenzer et al., 2007; Yamagishi, 1997). Therefore, it is recommended that communicators use both qualitative and quantitative estimates of risk, with the latter preferably expressed through simple frequencies, for example: "the risk is very highabout 7 in every ten people are at risk." Also, consistent denominators should be used to compare probabilities (Trevena et al., 2013). One caveat is that focusing on simple numbers can backfire. For example, dropping case numbers can promote a false sense of security. This can be counteracted by shifting the focus from the number of cases to the reproduction number $R$ and explaining in lay language why restrictions can only be eased when $R$ drops below a certain threshold. Another target for educational messaging is the inherent time delays in the availability and analysis of data, as there will always be a time lag between interventions and impacts.

Reproduction numbers and delays are examples of infectious disease model parameters. Future scenarios are often derived from computer modelling or epidemiology. The public is frequently exposed to terminology without necessarily possessing the foundational knowledge of how models are used within science. When communicating information from models, it is vital to frame the utility of the modelling accurately (e.g., precise numbers do not reflect specific predetermined outcomes; O'Connell and Hurley, 2009). It is crucial to proactively counter misconceptions that 'the models were wrong,' as models are not intended to predict predetermined realities but rather to simulate potential realities based on particular assumptions. Therefore, to the extent that disease models serve to change behaviour, their outcomes will change in response, meaning models can be accurate but not come true. This is known as the 'prophet's dilemma.' Another target for educational messaging is the socalled ' $\mathrm{Y} 2 \mathrm{~K}$ fallacy', where the public takes the absence of severe outcomes as evidence that the initial fears of public health officials and scientists were unwarranted and countermeasures an overreaction.

Recommendation 7-Empower people to act. Guiding how to act is only one part of the equation-people also need to be able to act as requested. Thus, in general, communication needs to be accompanied by appropriate measures to facilitate behaviour change and action. Communicators and policymakers, therefore, need to consider both practical and psychological barriers to desired behaviours, and people need to have the capability, opportunity, and motivation to engage in recommended actions (Michie et al., 2011; MacFarlane et al., 2020; Peters et al., 2018). Reviews of health interventions aimed at preventing infectious diseases find that strategies to enhance access to the resources needed to act are, therefore, also essential (Edwards et al., 2012). For example, recognizing that a person is more likely to comply with quarantine if they have the economic resources to sustain a period without work is critical to both policy intervention and communication.

Message framing is vital to fostering empowerment (Lakoff, 2010). For example, communications strategies that suggest people should 'calm down' imply that some people are in a panic, potentially creating further anxiety. The statement that 'we are getting on top of the crisis' is a positive message but reinforces a crisis. Thus, if the intention is to instil calmness and optimism, the framing of 'we are on the road to recovery' may be preferable. The public has been an important part of the collective response to the COVID-19 pandemic (Levy, 2020). Facing a common 
threat can elicit a shared sense of togetherness, encouraging people to look beyond their differences and respond with a heightened sense of collective responsibility (van Zomeren et al., 2008). Therefore, a critical role of government during a pandemic is to appeal to public solidarity and resilience (Jetten et al., 2020). In the context of self-efficacy, frames that promote agency and appeal to citizens' capacity to act are superior to frames that suggest people are passive recipients of instructions over which they have no control. This 'frailty' perspective risks suppressing community solidarity and resilience (Jetten et al., 2020; van Bavel et al., 2020). Harnessing the power of togetherness is critical-in recent data from nearly 6000 respondents across eleven countries, messaging and support for 'we are all in this together, and we all need to come out of it together' was the best predictor of adherence (Jetten et al., 2020). When people feel part of a group and that others support them, it reduces anxiety and stress, thereby improving physical and mental health (Haslam et al., 2018). Action-oriented frames are particularly well-suited to guide community responses, as people's responses to publichealth messaging during a pandemic are heavily driven by pragmatism (Davis et al., 2016; Davis and Lohm, 2020). People's capacity to act-work, domestic life, care responsibilities, etc.-is often at the forefront of their minds, and they have a desire to know what will work in the circumstances of their lives.

Community groups, businesses, and organisations also have specific expertise and local knowledge needed to devise implementable containment measures (Wynne, 2002). Industry representatives could be encouraged to consult more widely and present a plan for commencing commercial activity in a way that minimizes risk. Retail outlets have translated general physical distancing and hygiene requirements into specific, workable shop-floor practices that act as behaviour nudges. ${ }^{6}$ The guidance (e.g., floor markings that promote physical distancing, directional arrows for customer traffic, hand-sanitizer dispensers at retail store entrances) facilitates compliance. While governments have incorporated nudging tactics to encourage healthier lifestyle choices (Jones et al., 2013), some critics have warned that nudges have the potential to backfire due to differences in identity, norms, and values. It has been argued that longer-lasting attitude and behaviour change results from working with people's identities and their respective normative beliefs (Mols et al., 2015). In the following section, we discuss how arguably softer, less intrusive governance modes may be integrated through appealing to social norms.

Recommendation 8-Appeal to social norms. Psychology research has long demonstrated the effectiveness of social norming. Promoting desirable social norms, using both descriptive norms (everyone is doing it) and injunctive norms (it is the right thing to do), can promote desirable behaviours (Schultz et al., 2007). People are intrinsically motivated to look after their in-group; optimal communication, therefore, involves fostering solidarity (Cammett and Lieberman, 2020) and aligning messages with the social norm to take responsibility for people close to you and fellow citizens and avoid becoming a disease vector (Everett et al., 2020; Grant and Hofmann, 2011; Jordan et al., 2020).

However, social science research also reminds us that appealing to social norms can have oppressive effects by alienating and othering specific people (e.g., appeals to nationalism; Guttman and Salmon, 2004; Lupton, 2015). Social norming can foster a greater sense of marginalisation among some communities and perpetuate negative attitudes towards marginalised groups. Creating a sense of responsibility towards others by appealing to shared norms without alienating those who may not identify with such norms may be a tricky balance and further highlights the need for meaningful engagement with communities to develop targeted 'social norming' strategies. Important precedents for finding this balance have been seen within health campaigns designed by and for the LGBT community (Eliason et al., 2012).

Social norms are also embodied and reflected in people's emotional responses (Wacquant, 2005). Public-health campaigns are potentially more useful when they recognise these visceral dimensions of communication, and indeed there is a history of campaigns aimed at discouraging behaviours by eliciting disgust (Gagnon et al., 2010; Linnemann et al., 2013). However, the strategic appeal to emotional norms can also have an 'othering' effect: it risks propagating a sense of disgust towards particular behaviours and specific groups of people (Lupton, 2015). Again, this highlights the necessity of engaging with diverse communities to balance public health messaging (Habersaat et al., 2020).

Recommendation 9-Consider diverse community needs. It is vital to recognise that communities may not be affected by a pandemic, by communications, or by interventions-in the same way and to the same degree. For example, people with disabilities have specific and varied needs and can offer valuable insights that should be considered when planning communications. This includes making information accessible in various ways and applying risk management strategies that ensure people with disabilities can access preventive measures. Identifying and engaging with key groups may avoid missed opportunities before a rapid-spreading event. For example, an expert panel including doctors and political advisors argued that the governments in Australia missed sharing time-sensitive advice to reduce the spread of the coronavirus in high-risk migrant communities weeks before a spike in Melbourne, Victoria (Dalzell, 2020).

Language barriers need to be addressed through the timely translation of core communications into various languages (Stayner, 2020). Government officials are likely to be in a better position to understand the life circumstances, needs, strengths, and capabilities of multicultural and vulnerable communities if they work with trusted community leaders (Covello, 2003; Everett et al., 2020; National COVID-19 Health and Research Advisory Committee, 2020). Cross-cultural competency requires empathy, respect, and a willingness to ask if unsure. This manifests in a range of ways. For example, some cultures prefer face-to-face communication to promote important preventive information. Experiences with health services may be pivotal in people's willingness to return. If services like testing are not culturally aware, they may put people off. For example, a woman for whom face coverings must not be removed in public may prefer a female health worker to conduct a swab. Therefore, prevention strategies must be sensitive to spiritual, religious practices, and cultural norms.

Recommendation 10-Be proactive in combating misinformation. The pandemic has also seen a surge in misinformation and conspiracy theories, which have been accepted by a significant minority of Australians and call for a proactive approach (Pickles et al., 2020). Transparently providing factual and current information prevents subsequent susceptibility to emerging misinformation and conspiracy theories (Jolley and Douglas, 2017). As soon as a particular piece of misinformation (e.g., 'if you wear a mask it is safe to enter crowded environments') gains a certain amount of traction, it is advisable to inoculate the broader populace by scrutinizing the misinformation, pointing out the particular logical fallacy and the motivation behind its spread (Cook et al., 2017; van der Linden et al., 2017). In the mask example, the fallacy would be jumping to an unwarranted conclusion, namely that a mask effectively filters the virus, and the motivation may be an overemphasis on stimulating economic 
activity rather than a safe exit strategy. The same rationale applies to more outrageous conspiracy theories, where it can be useful to expose the tell-tale signs of conspiratorial thinking to help people be better prepared when they encounter conspiratorial ideas (Douglas et al., 2017; Lewandowsky and Cook, 2020). Combating misinformation using specific techniques can significantly reduce the spread of dangerous misinformation. These include traditional fact-checking and debunking approaches (Ecker et al., 2020; MacFarlane et al., 2020; Paynter et al., 2019), and also reminding people to think carefully about the accuracy of online information and consider the credibility of the source before sharing information on social media (Pennycook et al., 2020). It should also be noted that building trust in government and health authorities will be a protective factor, as mistrust is one of the drivers of conspiracy beliefs (Pierre, 2020).

In summary, we have presented ten recommendations for effective communications in the era of COVID-19:

1. Engage in clear communication

2. Strive for maximum credibility

3. Communicate with empathy

4. Communicate with openness, frankness, and honesty

5. Recognise that uncertainty is inevitable

6. Account for levels of health literacy and numeracy

7. Empower people to act

8. Appeal to social norms

9. Consider diverse community needs

10. Be proactive in combating misinformation

\section{Translating the ten recommendations into an effective communications strategy}

Collectively, our ten recommendations emphasize the benefits of meaningful civic engagement. We hasten to add that in practice, it may not be possible to follow all recommendations; for example, there might be tension between our focus on two-way communication and Recommendation 6 to address potential health and numeracy literacy deficits, which may involve some one-way communication. In such cases, communicators will need to resolve tensions through focal prioritisation. Moreover, there will be constraints arising from the governing realities that curtail engagement, and these constraints will be especially severe during crises. In our view, this makes it particularly prudent for governments to pursue ongoing civic engagement, for example, through community reference groups, described in the following section. We also discuss the potential role and associated challenges of digital technologies during a public health emergency.

Community reference groups. Community reference groups can be consulted on an ongoing basis to represent the socio-cultural diversity of respective communities. Such groups are often best equipped to provide guidance on the lived experiences and perspectives of key groups that affect how people respond to messages and prevent disease. They allow planners to better appreciate community concerns and needs and potential opposition to specific intervention strategies.

In consulting with communities, there are inherent risks of conflict and disengagement. For example, significant sections of the community may oppose any government-imposed restrictions or fundamentally reject the legitimacy of the scientific method (e.g., Lewandowsky et al., 2016; Lewandowsky and Cook, 2020); in such cases, there may be little benefit of engagement (Leask, 2002). However, as long as some common ground can be found, a consultative approach can help develop more nuanced and inclusive response strategies and secure broader community support. Naturally, different groups will have other, and sometimes incompatible, needs and wants in many cases. In such cases, it is a government obligation to reconcile and weigh up such competing priorities and concerns to the extent possible. However, we note that even if genuine attempts to reconcile competing priorities are undertaken (which cannot be taken for granted given that governments may also have a competing agenda), the efficacy of communications will only be high if the decision making around the crisis response and the reconciliation is transparent.

Community reference groups can also advise appropriate messaging platforms and modes of communication (e.g., sign language, TV broadcast, SMS, various social media platforms) and the framing and tone of messages. In general, government communications advisors are encouraged to consider that digital communications platforms are fragmenting and engage in a range of digital media platforms to reach target groups. While one must assume that government advisors are aware of the fragmentation of media platforms and the need for a diversified approach, the evidence in many jurisdictions suggests a gap between awareness and action that needs to be bridged, especially with young adults (Veinberg, 2015). For example, Australian governments arguably did not always engage adequately with the younger generation and culturally and linguistically diverse groups, leading to demonstrable communication failures (Dalzell, 2020; Roberts, 2020; Stayner, 2020). Effectively bridging this gap will require additional resourcing and prioritisation by the government.

Some of the groups that should be considered explicitly in government community engagement include:

- Young children (up to 12 years old) and their families;

- Secondary school children

- Young adults (aged 18-30 years old)

- Older adults $(70+$ years old) and those living in residential care communities

- Indigenous people

- Gender diverse/LGBTQ+communities

- People affected by natural disasters (e.g., bushfires, floods, hurricanes)

- People with life-threatening conditions (e.g., immunocompromised patients)

- Hearing-impaired community

- Vision-impaired community

More generally, and as noted in our recommendations, it is essential to acknowledge that norms and modes of communication differ between various social and cultural communities. The impact of communications is increased by working in conjunction with community reference groups to provide ongoing input into the decisions that affect them. Existing groups may suffice to provide this role (e.g., in Australia, the Aboriginal and Torres Strait Islander Advisory Group on COVID-19), but new groups would need to be in some cases formally established. Groups should be provided with an opportunity to delineate and appraise the risks as they perceive them (Renn, 2008). Representative organisations and support communities (e.g., Vision Australia, Deaf Australia) should be approached to assist and advise on forming these groups. There may be groups, such as the elderly or teachers, whose health may be affected, or sectors such as the hospitality industry that have a direct financial interest. Representatives from these groups, which could be identified via community group or professional association membership, should be considered participants in a deliberative process.

The role of emerging digital tools. Inevitably, combining the proposed foundations and the ten recommendations into an effective government communications strategy will enjoin 
technology use. Tracing applications are anticipated to help identify outbreaks and contain the spread of diseases, including COVID-19 (Parker et al., 2020). However, while the use of some digital technologies may be proportionate and deemed necessary by public health officials during a pandemic, issues of social license, due diligence, and new legislation require careful consideration and communication. Citizens' perceptions of transparency and their trust in the government mediate their use of digital platforms (Song and Lee, 2016). Public trust can erode rapidly if policymakers do not communicate how mobile tracing applications work (Denhardt and Denhardt, 2009; Stanley and Granick, 2020). A simplistic or overly optimistic understanding of emerging tools can be counterproductive, invading privacy, and not resulting in commensurate benefits (Stanley and Granick, 2020). These factors have arguably contributed to the suboptimal uptake of the 'COVIDSafe' tracing app in Australia (Chugh, 2020; Dennis et al., 2020; Garrett et al., 2020).

Rapidly fielded technologies are unlikely to be a 'magic bullet' and achieve the desired palliative effect. When government policymakers support the use of emerging tools during a period of crisis, they face at least three challenges. Firstly, there is a temptation to apply technology to support policy decisions that impact a broad audience (Song and Lee, 2016). However, the problem is that technologies are changing rapidly; many are immature and are often fielded with both known and unknown defects (Hyland-Wood, 2008). Secondly, software systems are inherently complex and have unintended consequences when widely deployed, and the 'law of unintended consequences' always applies to software (Tenner, 1996). Thirdly, it is unknown in advance how people will react to new technologies. The COVID-19 pandemic has shown that data collected on public health is often incomplete (Garrett et al., 2020; Stanley and Granick, 2020). Various populations and demographics may be represented differently in the collected data. Decision-making could unintentionally omit entire populations or get an incomplete representation of others, leading to bias in deploying public health resources (Stanley and Granick, 2020). In keeping with our recommendations, translating an effective communications strategy should reflect an understanding of data sovereignty concerning First Nations and Indigenous peoples (Daly et al., 2019; Kukutai and Taylor, 2016). Oversight by an inclusive and comprehensive oversight board is central to public policy design and evaluation (Ferretti et al., 2020).

\section{Limitations}

The research literature is drawn from public health and risk communication, cognitive and social psychology, sociology, and policy studies. We acknowledge that our recommendations are not based on a systematic literature review; instead, the analysis was guided by the authors' expertise in the subject and synthesis of the literature in our respective fields.

\section{Conclusion}

We have defined a series of ten recommendations for pandemic communications drawing on diverse disciplinary lenses. Effective government crisis communication relies on engagement. Enlisting a two-way communication process for ongoing public action and the speed and scale of government response is vital. The foundations of our proposed communications approach are public trust to harness public cooperation and sustain behaviours, underpinned by transparency and civic engagement. We acknowledge that the presented framework rests on a set of normative preferences that are not universally shared; therefore, the framework will need to be adjusted to fit alternative normative contexts. We also acknowledge that our framework is a principles-based and evidence-informed one constrained by the realities of governing. For example, in any democratic society, there will be a diversity of values and perspectives and contested evidence and knowledge. We believe our article can serve as a guide for policymakers and communicators and provide value as an educational tool, a basis for public debate, a guide for empirical investigation, and a yardstick for holding governments to account. We hope that our recommendations prove useful for practitioners and call on theoretical and applied communications researchers to test and critically evaluate our framework empirically. Responding to pandemics is as much about communications studies, social psychology, and policy studies, as it is about epidemiology and virology. Effective public health communications in the era of COVID-19, therefore, require a genuinely cross-disciplinary perspective grounded in evidence and reflects the values of democratic societies.

\section{Data availability}

Data sharing not applicable to this article as no datasets were generated or analysed during this study.

\section{Received: 6 July 2020; Accepted: 17 December 2020;}

Published online: 27 January 2021

\section{Notes}

1 Statistics from Worldometer COVID-19 dashboard as of Dec, 14, 2020; https://www. worldometers.info/coronavirus/\#countries

2 The authors of the present article were the authors of the relevant chapters of this report (Chapter 5-The Importance of Public Trust, Transparency and Civic

Engagement and Chapter 11-Clarity of Communication). The report chapters provided only high-level communications recommendations. As such, while there is some inevitable duplication in terms of the framework; the current paper fleshes out the recommendations and thus is composed almost entirely of material that did not feature in the report.

3 The authors' expertise spans the disciplines of public health and risk communication, cognitive and social psychology, sociology and policy studies.

4 For example, on 22 May 2020, newspapers in the United Kingdom reported how Dominic Cummings, a senior aide to the British prime minister, broke the lockdown rules and travelled over $400 \mathrm{~km}$ to a family home. Mr. Cummings refused to apologise or resign, as others who had acted in a similar manner had.

5 Within the health care discipline, this is known as the Capability, Opportunity and Motivation Model of Behaviour (COM-B; Michie et al., 2011).

6 Popularised by Thaler and Sunstein (2008; p. 6), a nudge is defined as "any aspect of the choice architecture that alters people's behaviour in a predictable way, without forbidding any options or significantly changing their economic incentives."

\section{References}

Adler RP, Goggin J (2005) What do we mean by "civic engagement"? J Transform Educ 3(3):236-253. https://doi.org/10.1177/1541344605276792

Agley J (2020) Assessing changes in US public trust in science amid the COVID-19 pandemic. Public Health 183:122-125. https://doi.org/10.1016/j.puhe.2020.05.004

Alford J, Head BW (2017) Wicked and less wicked problems: a typology and a contingency framework. Policy Soc 36(3):397-413. https://doi.org/10.1080/ 14494035.2017.1361634

Allen J, Gluckman P, Bardsley A, Sridhar H (2020) New Zealand's place in the world: the implications of COVID-19 (The Future Is Now). University of Auckland, p. 18

Australian Commission on Safety and Quality in Health Care and Australian Institute of Health and Welfare. Exploring healthcare variation in Australia: analyses resulting from an OECD study. https://www.aihw.gov.au/reports/ australias-health/health-literacy

Betsch C, Sachse K (2013) Debunking vaccination myths: strong risk negations can increase perceived vaccination risks. Health Psychol 32(2):146-155. https:// doi.org/10.1037/a0027387

Boele-Woelki K, Francisco JS, Hahn U, Herz J (2018) How we can rebuild trust in science-and why we must. Angewandte Chemie Int Edn 57 (42):13696-13697. https://doi.org/10.1002/anie.201805342

Briñol P, Petty RE (2009) Source factors in persuasion: a self-validation approach. Eur Rev Soc Psychol 20(1):49-96. https://doi.org/10.1080/10463280802643640

Burgess J, Green J (2018) Youtube: online video and participatory culture (2nd edn). Polity Press 
Bursztyn L, Rao A, Roth C, Yanagizawa-Drott D (2020) Misinformation during a pandemic. NBER. https://www.nber.org/papers/w27417.pdf

Cairney P (2015) How can policy theory have an impact on policymaking? The role of theory-led academic-practitioner discussions. Teach Public Admin 33 (1):22-39. https://doi.org/10.1177/0144739414532284

Cairney P (2016) The politics of evidence-based policy making. Palgrave Macmillan

Cammett M, Lieberman E (2020) Building solidarity: challenges, options, and implications for COVID-19 responses (No. 4; COVID-19 Rapid Response Impact Initiative. In: Edmond J (eds) Safra Center for Ethics, Harvard, p. 34

Carter SM, Rychetnik L, Lloyd B, Kerridge IH, Baur L, Bauman A, Hooker C, Zask A (2011) Evidence, ethics, and values: a framework for health promotion. Am J Public Health 101(3):465-472. https://doi.org/10.2105/AJPH.2010.195545

Cash D, Clark WC, Alcock F, Dickson N, Eckley N, Jäger J (2003) Salience, credibility, legitimacy and boundaries: linking research, assessment and decision making. SSRN Electronic J https://doi.org/10.2139/ssrn.372280

Chudleigh JH, Gould, DJ, Grol R, Moralejo D (2004). Interventions to improve hand hygiene compliance in patient care. In: The Cochrane Collaboration (ed) The Cochrane Database of Systematic Reviews. John Wiley \& Sons, Ltd., p. CD005186

Chugh R (2020, July 1) By persisting with COVIDSafe, Australia risks missing out on globally trusted contact tracing. The Conversation. https:// theconversation.com/by-persisting-with-covidsafe-australia-risks-missingout-on-globally-trusted-contact-tracing-141369

Cook J, Lewandowsky S, Ecker UKH (2017) Neutralizing misinformation through inoculation: exposing misleading argumentation techniques reduces their influence. PLoS ONE 12(5):e0175799. https://doi.org/10.1371/ journal.pone. 0175799

Covello VT (2003) Best practices in public health risk and crisis communication. J Health Commun 8(sup1):5-8. https://doi.org/10.1080/713851971

Daly A, Devitt K, Mann M (eds) (2019) Good data. Institute of Network Cultures. https://eprints.qut.edu.au/125605/

Dalzell S (2020, June 24) Government warned of coronavirus 'missed opportunity' to protect migrant communities before Victorian spike. Australian Broadcasting Corporation. https://www.abc.net.au/news/2020-06-24/governmentwarned-failing-engage-migrant-communities-coronavirus/12384800

Davis M, Flowers P, Lohm D, Waller E, Stephenson N (2016) Immunity, biopolitics and pandemics: public and individual responses to the threat to life. Body Soc 22(4):130-154. https://doi.org/10.1177/1357034X14556155

Davis M, Lohm D (2020) Pandemics, publics, and narrative. Oxford University Press

Denhardt RB, Denhardt JV (2009) Public administration: an action orientation (6th edn). Thomson/Wadsworth

Dennis S, Perfors A, Little, DR, White JP, Mitchell L, Geard N, Garrnett PM, Lewandowsky S (2020, May 15) 70\% of people surveyed said they'd download a coronavirus app. Only $44 \%$ did. Why the gap? https://theconversation.com/ 70-of-people-surveyed-said-theyd-download-a-coronavirus-app-only-44did-why-the-gap-138427

Devine D, Gaskell J, Jennings W, Stoker G (2020) Trust and the Coronavirus Pandemic: what are the consequences of and for trust? an early review of the literature. Polit Stud Rev 147892992094868. https://doi.org/10.1177/ 1478929920948684

Dobson AS, Robards B, Carah N (2018) Digital intimate publics and social media. https://doi.org/10.1007/978-3-319-97607-5

Douglas KM, Sutton RM, Cichocka A (2017) The psychology of conspiracy theories. Curr Direct Psychol Sci 26(6):538-542. https://doi.org/10.1177/ 0963721417718261

Ecker UKH, Hogan JL, Lewandowsky S (2017) Reminders and repetition of misinformation: helping or hindering its retraction? J Appl Res Memory Cogn 6 (2):185-192. https://doi.org/10.1016/j.jarmac.2017.01.014

Ecker UKH, O'Reilly Z, Reid JS, Chang EP (2020) The effectiveness of short-format refutational fact-checks. Br J Psychol 111(1):36-54. https://doi.org/10.1111/ bjop. 12383

Edwards R, Charani E, Sevdalis N, Alexandrou B, Sibley E, Mullett D, Loveday HP, Drumright LN, Holmes A (2012) Optimisation of infection prevention and control in acute health care by use of behaviour change: a systematic review. Lancet Infect Dis 12(4):318-329. https://doi.org/10.1016/S14733099(11)70283-3

Eliason MJ, DeJoseph J, Dibble SL, Chinn P (2012) LGBT health research: introduction to the special issue. J Homosex 59(6):761-764. https://doi.org/ 10.1080/00918369.2012.694751

Everett JAC, Colombatto C, Chituc V, Brady WJ, Crockett M (2020) The effectiveness of moral messages on public health behavioral intentions during the COVID-19 pandemic. Preprint at PsyArXiv. https://doi.org/10.31234/osf.io/9yqs8

Fancourt D, Steptoe A, Wright L (2020) The Cummings effect: politics, trust, and behaviours during the COVID-19 pandemic. The Lancet 396 (10249):464-465. https://doi.org/10.1016/S0140-6736(20)31690-1

Ferretti L, Wymant C, Kendall M, Zhao L, Nurtay A, Abeler-Dörner L, Parker M, Bonsall D, Fraser C (2020) Quantifying SARS-CoV-2 transmission suggests epidemic control with digital contact tracing. Science 368(6491):eabb6936. https://doi.org/10.1126/science.abb6936

Funk C, Kennedy B (2019) Public confidence in scientists has remained stable for decades. http://www.pewresearch.org/fact-tank/2017/04/06/publicconfidence-in-scientists-has-remained-stable-for-decades/

Gagnon M, Jacob JD, Holmes D (2010) Governing through (in)security: a critical analysis of a fear-based public health campaign. Critical Public Health 20 (2):245-256. https://doi.org/10.1080/09581590903314092

Garrett P, White J, Dennis S, Little D, Perfors A, Kashima Y, Lewandowsky S (2020) Attitudes of Australians to the Government's COVIDSafe contact tracing app. University of Melbourne. https://psychologicalsciences. unimelb.edu.au/research/hubs/chdh/news/attitudes-of-australians-to-thegovernments-covidsafe-contact-tracing-app

Gauchat G (2012) Politicization of science in the public sphere: a study of public trust in the United States, 1974 to 2010. Am Sociol Rev 77(2):167-187. https://doi.org/10.1177/0003122412438225

Gigerenzer G, Gaissmaier W, Kurz-Milcke E, Schwartz LM, Woloshin S (2007) Helping doctors and patients make sense of health statistics. Psychol Sci Public Interest 8(2):53-96

Grand A, Wilkinson C, Bultitude K, Winfield AFT (2012) Open science: a new "trust technology"? Sci Commun 34(5):679-689. https://doi.org/10.1177/ 1075547012443021

Grant AM, Hofmann DA (2011) It's not all about me: motivating hand hygiene among health care professionals by focusing on patients. Psychol Sci 22 (12):1494-1499. https://doi.org/10.1177/0956797611419172

Group of Eight Universities (2020) COVID-19 roadmap to recovery: a report for the nation (p. 192) [Research]. Group of Eight. https://go8.edu.au/wpcontent/uploads/2020/05/Go8-Road-to-Recovery.pdf

Gustafson A, Rice RE (2020) A review of the effects of uncertainty in public science communication. Public Understand Sci 29(6):614-633. https://doi.org/ $10.1177 / 0963662520942122$

Guttman N, Salmon CT (2004) Guilt, fear, stigma and knowledge gaps: ethical issues in public health communication interventions. Bioethics 18(6):531-552

Habersaat KB, Betsch C, Danchin M, Sunstein CR, Böhm R, Falk A, Brewer NT, Omer SB, Scherzer M, Sah S, Fischer EF, Scheel AE, Fancourt D, Kitayama S, Dubé E, Leask J, Dutta M, MacDonald NE, Temkina A, Butler R (2020) Ten considerations for effectively managing the COVID-19 transition. Nat Human Behav 4(7):677-687. https://doi.org/10.1038/s41562-020-0906-x

Han PKJ, Zikmund-Fisher BJ, Duarte CW, Knaus M, Black A, Scherer AM, Fagerlin A (2018) Communication of scientific uncertainty about a novel pandemic health threat: ambiguity aversion and its mechanisms. J Health Commun 23(5):435-444. https://doi.org/10.1080/10810730.2018.1461961

Haslam SA, Jetten J, Cruwys TD (2018) The new psychology of health: unlocking the social cure. Routledge

Haslam SA, Reicher S, Platow M (2011) The new psychology of leadership: identity, influence, and power. Psychology Press

Head BW (2007) Community engagement: participation on whose terms? Australian J Polit Sci 42(3):441-454. https://doi.org/10.1080/10361140701513570

Head BW (2010a) Reconsidering evidence-based policy: key issues and challenges. Policy Soc 29(2):77-94. https://doi.org/10.1016/j.polsoc.2010.03.001

Head BW (2010b) Reconsidering evidence-based policy: key issues and challenges. Policy Soc 29(2):77-94. https://doi.org/10.1016/j.polsoc.2010.03.001

Head BW (2011) Australian experience: civic engagement as symbol and substance. Public Admin Dev 31(2):102-112. https://doi.org/10.1002/pad.599

Head BW (2016) Toward more "evidence-informed" policy making? Public Admin Rev 76(3):472-484. https://doi.org/10.1111/puar.12475

Hyland-Wood D (2008) Metadata foundations for the life cycle management of software systems. Thesis. The University of Queensland, School of Information Technology and Electrical Engineering

Jetten J, Reicher SD, Haslam SA, Cruwys T (2020) Together apart: the psychology of COVID-19. Sage Publishing

Jolley D, Douglas KM (2017) Prevention is better than cure: addressing antivaccine conspiracy theories. J Appl Soc Psychol 47(8):459-469. https://doi. org/10.1111/jasp. 12453

Jones R, Pykett J, Whitehead M (2013) Psychological governance and behaviour change. Policy Polit 41(2):159-182. https://doi.org/10.1332/030557312X655422

Jordan J, Yoeli E, Rand DG (2020) Don't get it or don't spread it? Comparing selfinterested versus prosocially framed COVID-19 prevention messaging. Preprint at PsyArXiv. https://doi.org/10.31234/osf.io/yuq7x

Kendeou P, Walsh EK, Smith ER, O’Brien EJ (2014) Knowledge revision processes in refutation texts. Discourse Process 51(5-6):374-397. https://doi.org/ 10.1080/0163853X.2014.913961

Kovic M, Füchslin T (2018) Probability and conspiratorial thinking: probability and conspiratorial thinking. Appl Cogn Psychol 32(3):390-400. https://doi org/10.1002/acp.3408

Kreuter MW, Strecher VJ, Glassman B (1999) One size does not fit all: the case for tailoring print materials. Ann Behav Med 21(4):276-283. https://doi.org/ $10.1007 /$ BF02895958 
Kuhlmann E (2006) Traces of doubt and sources of trust: health professions in an uncertain society. Curr Sociol 54(4):607-620. https://doi.org/10.1177/ 0011392106065092

Kukutai T, Taylor J (2016) Indigenous data sovereignty: toward an agenda. ANU Press

Lakoff G (2010) Moral politics: how liberals and conservatives think. University of Chicago Press

Leask J (2002) Vaccination and risk communication: summary of a workshop, Arlington Virginia, USA, 5-6 October 2000. J Paediatr Child Health 38 (2):124-128. https://doi.org/10.1046/j.1440-1754.2002.00791.x

Leask J, Hooker C (2020) How risk communication could have reduced controversy about school closures in Australia during the COVID-19 pandemic. Public Health Res Practice 30(2) https://doi.org/10.17061/ phrp3022007

Leiserowitz AA, Maibach EW, Roser-Renouf C, Smith N, Dawson E (2013) Climategate, public opinion, and the loss of trust. Am Behav Scientist 57 (6):818-837. https://doi.org/10.1177/0002764212458272

Levy A (2020, May 15) Coronavirus: how times of crisis reveal our emotional connection with strangers. The Conversation. https://theconversation.com/ coronavirus-how-times-of-crisis-reveal-our-emotional-connection-withstrangers-136652

Lewandowsky S, Cook J (2020) The conspiracy theory handbook. http://sks.to/ conspiracy

Lewandowsky S, Ecker UKH, Cook J (2017) Beyond misinformation: understanding and coping with the "post-truth" era. J Appl Res Memory Cogn 6 (4):353-369. https://doi.org/10.1016/j.jarmac.2017.07.008

Lewandowsky S, Gignac GE, Vaughan S (2013) The pivotal role of perceived scientific consensus in acceptance of science. Nat Clim Change 3(4):399-404. https://doi.org/10.1038/nclimate1720

Lewandowsky S, Mann ME, Brown NJL, Friedman H (2016) Science and the public: debate, denial, and skepticism. J Soc Polit Psychol 4(2):537-553. https://doi.org/10.5964/jspp.v4i2.604

Lewandowsky S, Risbey JS, Smithson M, Newell BR, Hunter J (2014) Scientific uncertainty and climate change: Part I. Uncertainty and unabated emissions. Clim Change 124(1-2):21-37. https://doi.org/10.1007/s10584-014-1082-7

Lewis JM (2006) Being around and knowing the players: networks of influence in health policy. Soc Sci Med 62(9):2125-2136. https://doi.org/10.1016/j. socscimed.2005.10.004

Linnemann T, Hanson L, Williams LS (2013) 'With scenes of blood and pain': crime control and the punitive imagination of the meth project. Br J Criminol 53(4):605-623. https://doi.org/10.1093/bjc/azt008

Lupton D (2015) The pedagogy of disgust: the ethical, moral and political implications of using disgust in public health campaigns. Critical Public Health 25 (1):4-14. https://doi.org/10.1080/09581596.2014.885115

MacFarlane D, Hurlstone MJ, Ecker UKH (2020) Protecting consumers from fraudulent health claims: a taxonomy of psychological drivers, interventions, barriers, and treatments. Soc Sci Med 112790. https://doi.org/10.1016/j. socscimed.2020.112790

MacFarlane D, Tay LQ, Hurlstone, MJ, Ecker UKH (2020) Refuting spurious COVID-19 treatment claims reduces demand and misinformation sharing. Preprint at PsyArXiv. https://doi.org/10.31234/osf.io/q3mkd

Martin A, Gravelle TB, Baekkeskov E, Lewis J, Kashima Y (2019) Enlisting the support of trusted sources to tackle policy problems: The case of antimicrobial resistance. PLoS ONE 14(3):e0212993. https://doi.org/10.1371/ journal.pone.0212993

Massey PD, Pearce G, Taylor KA, Orcher L, Saggers S, Durrheim DN (2009) Reducing the risk of pandemic influenza in Aboriginal communities. Rural Remote Health 9(1290):1-7

Meyer G (2016) In science communication, why does the idea of a public deficit always return? Public Understand Sci 25(4):433-446. https://doi.org/10.1177/ 0963662516629747

Michie S, van Stralen MM, West R (2011) The behaviour change wheel: a new method for characterising and designing behaviour change interventions. Implement Sci 6(1):42. https://doi.org/10.1186/1748-5908-6-42

Miranti R, Evans M (2019) Trust, sense of community, and civic engagement: lessons from Australia. J Community Psychol 47(2):254-271. https://doi.org/ $10.1002 /$ jcop. 22119

Mols F, Haslam SA, Jetten J, Steffens NK (2015) Why a nudge is not enough: a social identity critique of governance by stealth: why a nudge is not enough. Eur J Polit Res 54(1):81-98. https://doi.org/10.1111/1475-6765.12073

Mols F, Bell J, Head B (2020) Bridging the research-policy gap: the importance of effective identity leadership and shared commitment. Evidence Policy 16 (1):145-163. https://doi.org/10.1332/174426418X15378681300533

Moser SC (2010) Communicating climate change: history, challenges, process and future directions: communicating climate change. Wiley Interdiscipl Rev 1 (1):31-53. https://doi.org/10.1002/wcc.11

Mulgan G (2005) Government, knowledge and the business of policy making: the potential and limits of evidence-based policy. Evidence Policy 1(2):215-226
National COVID-19 Health and Research Advisory Committee (2020) Risks of resurgence of COVID-19 in Australia.

National Research Council (1989) Improving risk communication. The National Academies Press

O'Connell E, Hurley F (2009) A review of the strengths and weaknesses of quantitative methods used in health impact assessment. Public Health 123 (4):306-310. https://doi.org/10.1016/j.puhe.2009.02.008

Parker MJ, Fraser C, Abeler-Dörner L, Bonsall D (2020) Ethics of instantaneous contact tracing using mobile phone apps in the control of the COVID-19 pandemic. J Med Ethics 46(7):427-431. https://doi.org/10.1136/medethics-2020-106314

Parkhurst JO (2017a) The politics of evidence: from evidence-based policy to the good governance of evidence. Routledge, Taylor \& Francis Group

Parkhurst JO (2017b) The politics of evidence: from evidence-based policy to the good governance of evidence. Routledge, Taylor \& Francis Group

Parkhurst JO, Abeysinghe S (2016) What Constitutes "Good" Evidence for Public Health and Social Policy-making? From Hierarchies to Appropriateness. Social Epistemol 30(5-6):665-679. https://doi.org/10.1080/02691728.2016.1172365

Paynter J, Luskin-Saxby S, Keen D, Fordyce K, Frost G, Imms C, Miller S, Trembath D, Tucker M, Ecker U (2019) Evaluation of a template for countering misinformation-Real-world Autism treatment myth debunking. PLOS ONE 14(1): e0210746. https://doi.org/10.1371/journal.pone.0210746

Pennycook G, McPhetres J, Zhang Y, Lu JG, Rand DG (2020) Fighting COVID19 misinformation on social media: Experimental evidence for a scalable accuracy nudge intervention. Preprint at PsyArXiv. https://doi.org/ 10.31234/osf.io/uhbk9

Peters G-JY, Ruiter RAC, ten Hoor GA, Kessels LTE, Kok G (2018) Towards consensus on fear appeals: a rejoinder to the commentaries on Kok, Peters, Kessels, ten Hoor, and Ruiter (2018). Health Psychol Review 12(2):151-156. https://doi.org/10.1080/17437199.2018.1454846

Peters RG, Covello VT, McCallum DB (1997) The determinants of trust and credibility in environmental risk communication: an empirical study. Risk Anal 17(1):43-54

Petersen MB (2020, March 9) The unpleasant truth is the best protection against the coronavirus. Politiken. https://pure.au.dk/portal/files/181464339/The_unpleasant_ truth is the best protection_against coronavirus_Michael_Bang_Petersen.pdf

Pfattheicher S, Nockur L, Böhm R, Sassenrath C, Petersen MB (2020) The emotional path to action: empathy promotes physical distancing and wearing face masks during the COVID-19 pandemic. Preprint at PsyArXiv. https://doi. org/10.31234/osf.io/y2cg5

Pham D (2016) Public engagement is key for the future of science research. Npj Sci Learn 1(1):16010. https://doi.org/10.1038/npjscilearn.2016.10

Pickles K, Cvejic E, Nickel B, Copp T, Bonner C, Leask J, Ayre J, Batcup C, Cornell S, Dakin T, Dodd R, Isautier JM, McCaffery KJ (2020) COVID-19: beliefs in misinformation in the Australian community. Public Global Health. https:// doi.org/10.1101/2020.08.04.20168583

Pierre JM (2020) Mistrust and misinformation: a two-component, socio-epistemic model of belief in conspiracy theories. J Soc Polit Psychol 8(2):617-641. https://doi.org/10.5964/jspp.v8i2.1362

Renn O (2008) Risk governance: coping with uncertainty in a complex world. Earthscan

Renn O, Walker KD (eds) (2008) Global risk governance: concept and practice using the irgc framework (Vol. 1). Springer, Netherlands

Reynolds B, Quinn SC (2008) Effective communication during an influenza pandemic: the value of using a crisis and emergency risk communication framework. Health Promot Practice 9(4_suppl):13S-17S. https://doi.org/ $10.1177 / 1524839908325267$

Roberts S (2020) Coronavirus: blaming millennials for spreading COVID-19 fails to see the bigger picture. Retrieved 1 October 2020, from https://lens.monash edu/@politics-society/2020/07/07/1380791/coronavirus-blaming-millennialsfor-spreading-covid-19-fails-to-see-the-bigger-picture

Sanderson I (2009) Intelligent policy making for a complex world: pragmatism, evidence and learning. Polit Stud 57(4):699-719. https://doi.org/10.1111/ j.1467-9248.2009.00791.x

Sandman P, Lanard J (2020) COVID-19: The CIDRAP Viewpoint (Center for Infectious Disease Research and Policy) [Research]. University of Minnesota. https://www.cidrap.umn.edu/sites/default/files/public/downloads/cidrapcovid19-viewpoint-part2.pdf

Schultz PW, Nolan JM, Cialdini RB, Goldstein NJ, Griskevicius V (2007) The constructive, destructive, and reconstructive power of social norms. Psychol Sci 18(5):429-434. https://doi.org/10.1111/j.1467-9280.2007.01917.x

Seeger MW (2006) Best practices in crisis communication: an expert panel process. J Appl Commun Res 34(3):232-244. https://doi.org/10.1080/00909880600769944

Siegrist M, Zingg A (2014) The role of public trust during pandemics: implications for crisis communication. Eur Psychol 19(1):23-32. https://doi.org/10.1027/ 1016-9040/a000169

Simonov A, Sacher S, Dubé JP, Biswas S (2020) The persuasive effect of Fox News: non-compliance with social distancing during the COVID-19 pandemic NBER. https://www.nber.org/papers/w27237.pdf 
Song C, Lee J (2016) Citizens' use of social media in government, perceived transparency, and trust in government. Public Perform Manag Rev 39 (2):430-453. https://doi.org/10.1080/15309576.2015.1108798

Stanley J, Granick JS (2020) The Limits of Location Tracking in an Epidemic. ACLU. https://www.aclu.org/sites/default/files/field_document/limits_of_location_ tracking_in_an_epidemic.pdf

Stayner T (2020, March 26) As in-language communication about COVID-19 is harnessed to reach multicultural groups, advocates warn minority communities must not be forgotten. SBS News. https://www.sbs.com.au/news/ australia-s-minority-communities-urgently-need-covid-19-resources

Steffens NK, Haslam SA, Reicher SD, Platow MJ, Fransen K, Yang J, Ryan MK, Jetten J, Peters K, Boen F (2014) Leadership as social identity management: Introducing the Identity Leadership Inventory (ILI) to assess and validate a four-dimensional model. Leadership Quart 25(5):1001-1024. https://doi.org/ 10.1016/j.leaqua.2014.05.002

Swerrisen H (2020, May 13) The new normal: how we'll live with COVID-19 [Research]. Grattan Institute. https://johnmenadue.com/hal-swerissen-thenew-normal-how-well-live-with-covid-19/

Tangney P (2017) Climate adaptation policy and evidence: understanding the tensions between politics and expertise in public policy. Routledge/Taylor \& Francis Group

Tenner E (1996) Why things bite back: technology and the revenge of unintended consequences (1st edn). Knopf

Thompson G (2013) Introducing functional grammar. Routledge

Trevena LJ, Zikmund-Fisher BJ, Edwards A, Gaissmaier W, Galesic M, Han PK, King J, Lawson ML, Linder SK, Lipkus I, Ozanne E, Peters E, Timmermans D, Woloshin S (2013) Presenting quantitative information about decision outcomes: a risk communication primer for patient decision aid developers. BMC Medi Informat Decision Making 13(S2):S7. https://doi.org/10.1186/ 1472-6947-13-S2-S7

van Bavel JJ, Baicker K, Boggio PS, Capraro V, Cichocka A, Cikara M, Crockett MJ, Crum AJ, Douglas KM, Druckman JN, Drury J (2020) Using social and behavioural science to support COVID-19 pandemic response. Preprint at PsyArXiv https://doi.org/10.31234/osf.io/y38m9, https://doi.org/10.1038/ s41562-020-0884-z

van der Bles A, Linden S van der, Freeman A, Spiegelhalter D (2020) The effects of communicating uncertainty on public trust in facts and numbers. https://doi. org/10.17605/OSF.IO/MT6S7

van der Linden S, Maibach E, Cook J, Leiserowitz A, Lewandowsky S (2017) Inoculating against misinformation. Science 358(6367):1141.2-1142. https:// doi.org/10.1126/science.aar4533

van Zomeren M, Postmes T, Spears R (2008) Toward an integrative social identity model of collective action: a quantitative research synthesis of three sociopsychological perspectives. Psychol Bullet 134(4):504-535. https://doi.org/ 10.1037/0033-2909.134.4.504

Veinberg S (2015) Digital native's attitude towards news sources. Public Relation Rev 41(2):299-301. https://doi.org/10.1016/j.pubrev.2014.11.004

Wacquant L (2005) Carnal connections: on embodiment, apprenticeship, and membership. Qualit Sociol 28(4):445-474. https://doi.org/10.1007/s11133-005-8367-0

Waszak PM, Kasprzycka-Waszak W, Kubanek A (2018) The spread of medical fake news in social media-The pilot quantitative study. Health Policy Technol 7(2):115-118. https://doi.org/10.1016/j.hlpt.2018.03.002

Whyte KP, Crease RP (2010) Trust, expertise, and the philosophy of science. Synthese 177(3):411-425. https://doi.org/10.1007/s11229-010-9786-3

Wilson D, Sperber D (2002) Truthfulness and relevance. Mind 111(443):583-632. https://doi.org/10.1093/mind/111.443.583

Wise T, Zbozinek TD, Michelini G, Hagan CC, Mobbs D (2020) Changes in risk perception and protective behavior during the first week of the COVID-19 pandemic in the United States. Preprint at PsyArXiv. https://doi.org/10.31234/osf.io/dz428, https://doi.org/10.1098/rsos.200742, https://royalsocietypublishing.org

Wynne B (2002) Risk and environment as legitimatory discourses of technology: reflexivity inside out? Curr Sociol 50(3):459-477. https://doi.org/10.1177/ 0011392102050003010

Wynne B (2006) Public engagement as a means of restoring public trust in science-hitting the notes, but missing the music? Public Health Genom 9 (3):211-220. https://doi.org/10.1159/000092659

Yamagishi K (1997) When a $12.86 \%$ mortality is more dangerous than $24.14 \%$ : implications for risk communication. Appl Cogn Psychol 11:495-506

\section{Acknowledgements}

The authors acknowledge the Group of Eight (Go8) Roadmap to Recovery - A Report for the Nation project and the valuable facilitation by the Hunt Laboratory for Intelligence Research at the University of Melbourne https://huntlab.science.unimelb.edu.au/home/ research/roadmap/. JG receives funding from the Australian Research Council (DE200100767). JL receives funding from the World Health Organisation, National Centre for Immunisation Research and Surveillance, and the National Health and Medical Research Council. UKHE receives funding from the Australian Research Council (FT190100708)

\section{Rights and permissions}

This work is licensed under a Creative Commons Attribution 3.0 International License. The images or other third-party material in this article are included in the article's Creative Commons license, unless indicated otherwise in the credit line; if the material is not included under the Creative Commons license, users will need to obtain permission from the license holder to reproduce the material. To view a copy of this license, visit http://creativecommons.org/licenses/by/3.0/.

\section{Competing interests}

The authors declare no competing interests.

\section{Additional information}

Correspondence and requests for materials should be addressed to B.H.-W.

Reprints and permission information is available at http://www.nature.com/reprints

Publisher's note Springer Nature remains neutral with regard to jurisdictional claims in published maps and institutional affiliations.

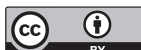

Open Access This article is licensed under a Creative Common Attribution 4.0 International License, which permits use, sharing, adaptation, distribution and reproduction in any medium or format, as long as you give appropriate credit to the original author(s) and the source, provide a link to the Creative Commons license, and indicate if changes were made. The images or other third party material in this article are included in the article's Creative Commons license, unless indicated otherwise in a credit line to the material. If material is not included in the article's Creative Commons license and your intended use is not permitted by statutory regulation or exceeds the permitted use, you will need to obtain permission directly from the copyright holder. To view a copy of this license, visit http://creativecommons.org/ licenses/by/4.0/

(C) The Author(s) 2021 